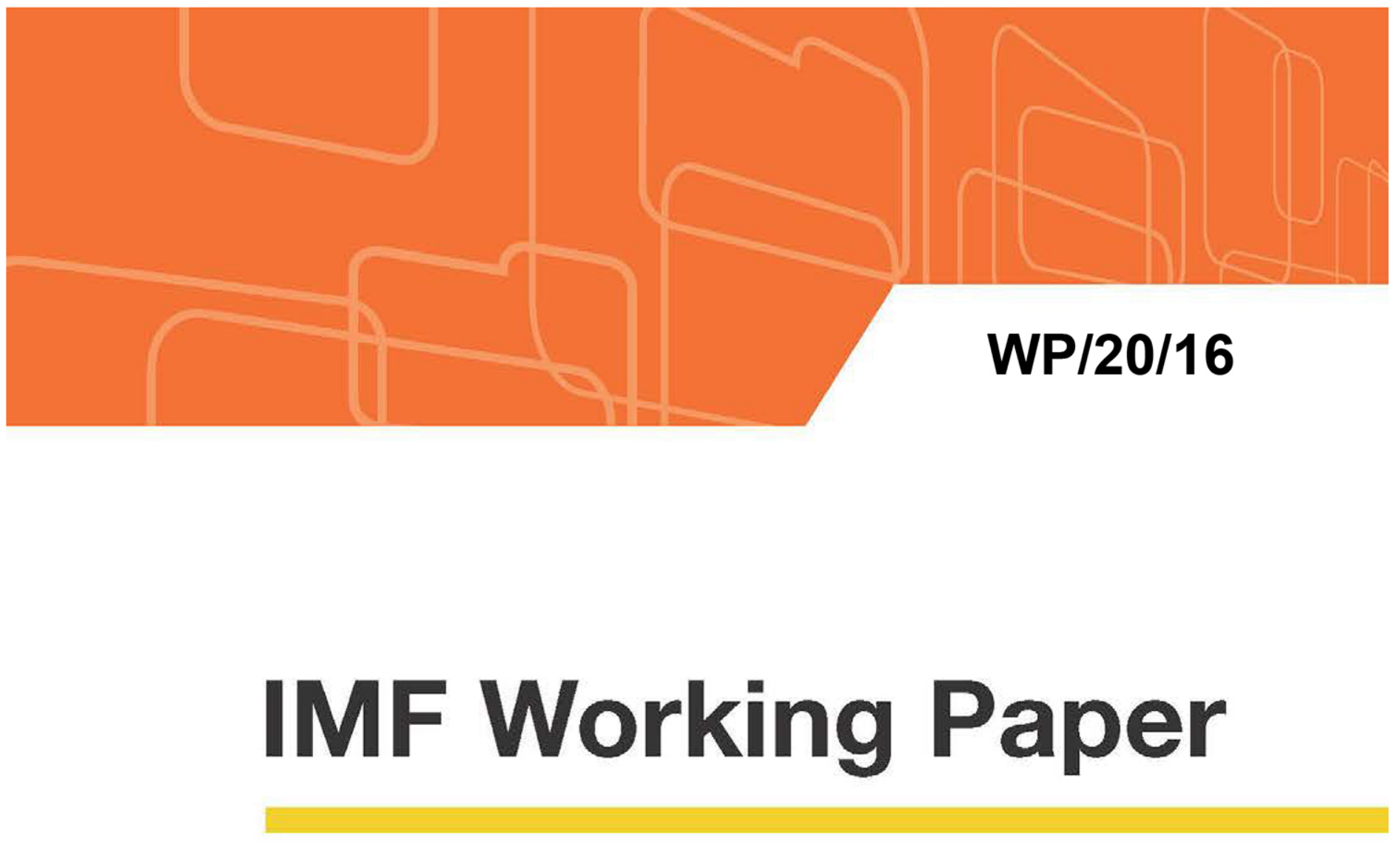

\title{
Effectiveness and Equity in Social Spending: The Case of Spain
}

by Svetlana Vtyurina

IMF Working Papers describe research in progress by the author(s) and are published to elicit comments and to encourage debate. The views expressed in IMF Working Papers are those of the author(s) and do not necessarily represent the views of the IMF, its Executive Board, or IMF management. 


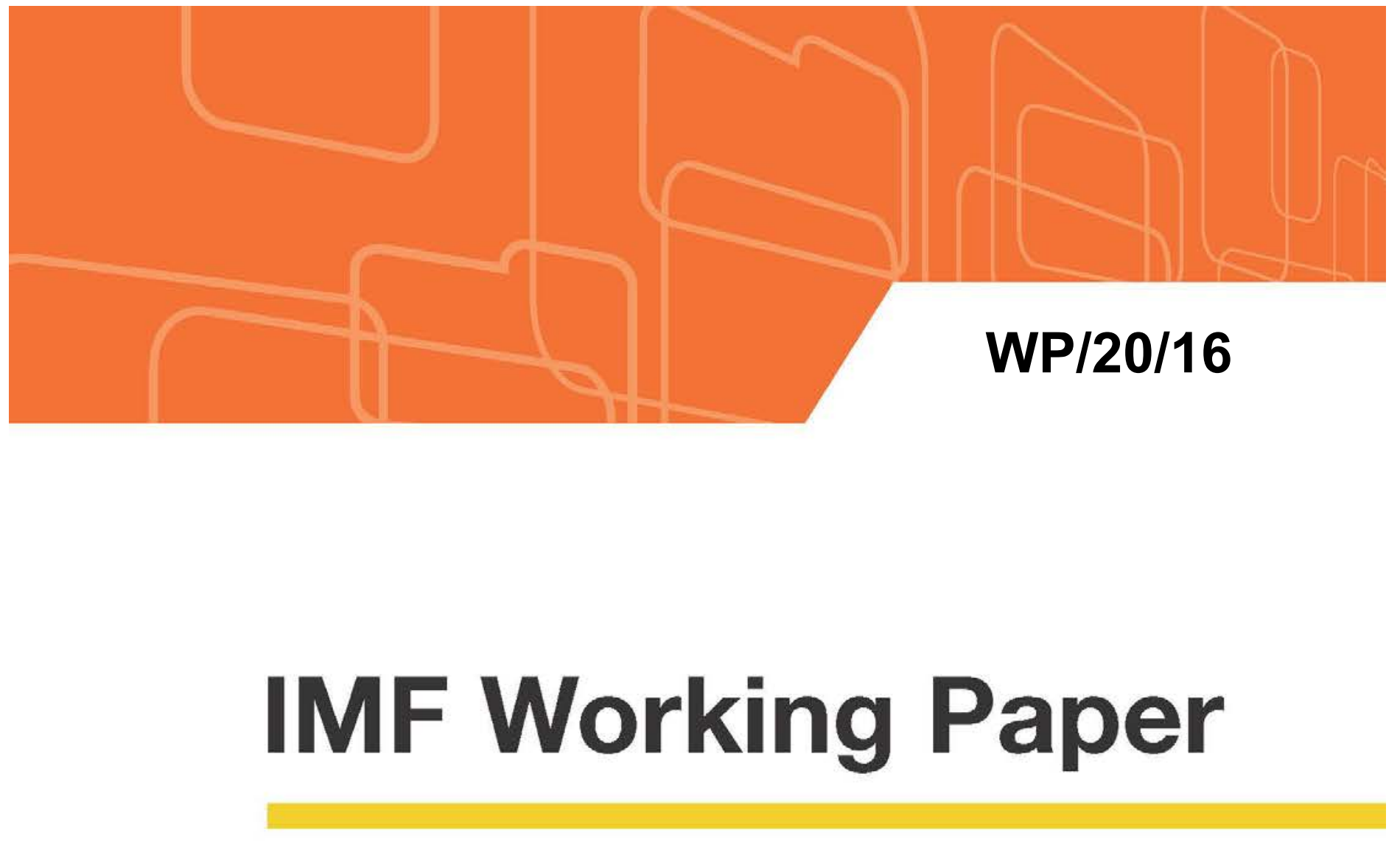

\section{Effectiveness and Equity in Social Spending: The Case of Spain}

by Svetlana Vtyurina

IMF Working Papers describe research in progress by the author(s) and are published to elicit comments and to encourage debate. The views expressed in IMF Working Papers are those of the author(s) and do not necessarily represent the views of the IMF, its Executive Board, or IMF management.

$$
\text { I N T E R N A T I O N A L M O N E T A R Y F U N D }
$$




\title{
IMF Working Paper
}

European Department

\section{Effectiveness and Equity in Social Spending: The Case of Spain \\ Prepared by Svetlana Vtyurina ${ }^{1}$}

Authorized for distribution by Andrea Schaechter

January 2020

IMF Working Papers describe research in progress by the author(s) and are published to elicit comments and to encourage debate. The views expressed in IMF Working Papers are those of the author(s) and do not necessarily represent the views of the IMF, its Executive Board, or IMF management.

\begin{abstract}
Spain is experiencing sustained economic and social disparities in several areas. Social spending policies have a heightened responsibility to respond but are challenged by high public debt and pressures from an aging society. This study takes stock of the level and effectiveness of public social expenditure from a cross-country and macroeconomic view, complementing recent targeted spending reviews. The results suggest that social protection spending should aim to improve redistribution through better targeting the most vulnerable while more effective education and active labor market policies should aim to create more equal opportunities and income prospects. In some areas more fiscal resources are needed. But social spending alone cannot reduce inequality, and efforts also should be directed toward making the labor market more inclusive.
\end{abstract}

JEL Classification Numbers: E62, H2, H75, I1, I2, I3, J62, J65

Keywords: Social Protection Expenditure, Redistribution, Spending Efficiency, Spain Author's E-Mail Address: svtyurina@,imf.org

\footnotetext{
${ }^{1}$ The author would like to thank the Banco de España, Ministerio de Economía y Empresa, Ministerio de Sanidad, Consumo y Bienestar Social, Ministerio de Trabajo, Migraciones y Seguridad Social, Andrea Schaechter, Maura Francese, and IMF seminar participants for helpful comments and suggestions. Jenny Lee's data assistance was invaluable. All remaining errors are my own.
} 
TABLE OF CONTENTS

Abstract

I. INTRODUCTION

II. OVERVIEW OF SOCIAL SPENDING

III. Sustainability, Adequacy, Redistribution And SuStainability OF Social Protection SPENDing

A. Pensions

B. Unemployment Protection

C. Other Social Assistance

D. Redistribution Impact on Inequality

IV. EFFiciency of SPending on Health, Education and ACtive Labor Market Policies

A. Healthcare

B. Education and Training

15

V. Takeaways and Policy Recommendations

REFERENCES

\section{BOXES}

1. What is Social Spending?

2. Minimum Income Schemes

3. Recent Reforms and Savings in the Healthcare Sector

\section{Figures}

1. Social Protection Expenditure, 2017

2. Pension Expenditure and Benefits

3. Unemployment Protection

4. Family Benefits and Minimum Income Support

5. At Risk-of-Poverty

6. Gini Coefficient

7. Indicators of Redistribution

8. Intergenerational Inequity

9. Means-Testing of Social Spending

10. Selected Indicators in the Healthcare Sector

11. Income Mobility across

12. Selected Education and Active Labor Market Policy Indicators

\section{TABLES}

1. Selected Countries: Social Protection and Health Expenditure, 2017

2. Public Finances and Social Protection Spending, 2007-18 


\title{
I. INTRODUCTION
}

\begin{abstract}
A harsh social fallout from the global financial crisis brought to the fore income inequalities in many countries and led to calls for increases in social spending. This came at a time when the fiscal space was generally limited due to high debt levels (Chen and others; IMF 2014). Over the last decade, Spain acted on the social front by raising allowances to poor families with children, long-term unemployment benefits, student stipends, and the minimum wage. Pensions continued to rise in real terms against adverse population dynamics, which implies significant spending pressures over the medium to long term. In 2019, Spain's public debt level is still close to 100 percent of GDP, nearly three times as high as in 2007.
\end{abstract}

In this context, there is merit to assessing the delivery, adequacy, and effectiveness of social spending. International experience shows that a more efficient provision of public expenditure could yield better outcomes for a given cost or create additional resources to raise outcomes where social indicators fare particularly weakly (see Box 1 for a definition of "social spending"). The Spanish government is committed to "efficient management of public resources [that] translates into allocation to those areas of expenditure with the highest priority or with the greatest potential for impact on society and the economy" (Stability Program Update 2019-22). The Independent Authority for Fiscal Responsibility (AIReF) was commissioned to carry out granular reviews in selected expenditure areas: healthcare spending (prescription drugs, hospital spending) at the regional level, a proposed minimum income scheme at the state level, subsidies and grants (e.g. university scholarships and housing), and active labor market policies (in particular, hiring incentives), which is one of the largest budget items in the area of subsidies. ${ }^{2}$

This study takes stock of the level and effectiveness of overall public social expenditure. By taking a cross-country and macroeconomic view, it sets a broad framework that builds on the advice of other stakeholders and recent studies by AIReF (2019) and Funcas (2019) on how to improve social outcomes more generally and lower the gaps across regions.

Chapter II provides an overview of the social protection system and spending trends. Chapter III discusses the main categories of social protection spending (pension, unemployment, social assistance), their sustainability, adequacy and efficiency in relation to social outcomes. Chapter IV examines on spending for health, education and training (active labor market policies) and its efficiency. Chapter V concludes with some policy recommendations. This paper does not analyze the new government's coalition agreement on social reform agenda in full, but a few proposals are mentioned in selected areas.

\footnotetext{
${ }^{2}$ Completed reviews can be found on http://www.airef.es/en/spending-review.
} 


\section{OVERVIEW OF SOCIAL SPENDING}

\section{Responsibility for social spending in Spain is shared across all levels of government.} Social spending is generally defined across three main categories (Box 1). While pensions and contributory unemployment systems remain centralized, the rest of the social protection has become a complex mosaic of support networks at different levels due to its mostly decentralized structure (Cavanillas, 2015; EC, 2015a). Both the national government and regional authorities have the power to legislate over benefits and to oversee their delivery. Generally, only pensions and contributory unemployment systems remain centralized whereas social services are largely managed and delivered at the regional and local levels. Legislative and tax practices vary by local authority. The social protection system covers sickness, retirement, unemployment, survival, disability, and family spending (maternity/paternity and transfers), and transfers for housing and to reduce exclusion. For education, a state ministry carries an overall mandate, but the Autonomous Communities make most of the decisions regarding their own education systems. The provision of active labor market policies is decentralized to the regional level.

\section{Social protection outlays in Spain are about half of total public} expenditures (Table 1). Spain spends less than the EU-average when measured relative to GDP (Figure 1). The administrative cost of Spain's social protection system is below the EU average. Most of Spanish social spending is public unlike in other EU countries which have greater private mandatory and voluntary outlays, in particular on pension and health spending. Social protection spending

Figure 1. Social Protection Expenditure, 2017

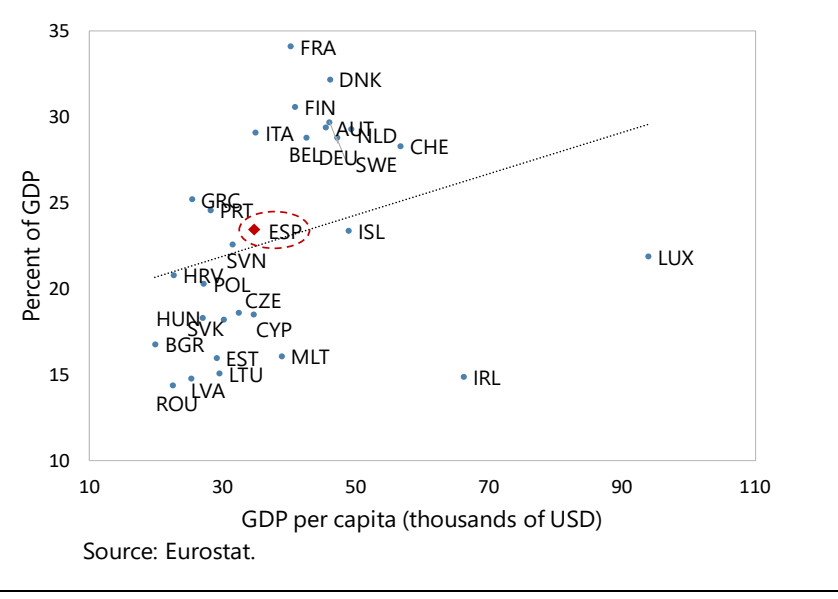
has followed a strongly countercyclical pattern over the past decade and acted as an automatic stabilizer during the crisis (Table 2). When output contracted sharply, social benefits in percent of GDP increased, mostly reflecting more outlays for unemployment benefits. The reverse pattern was observed with the recovery of the economy since 2014. In nominal and real terms, most social benefitsexcept subsidies for some years - continued to rise during the past decade but at much more moderate levels than pre-crisis. 


\section{Box 1. What is Social Spending?}

Social spending is defined as spending on social protection, education, and health following IMF (2019). ${ }^{1}$ Social protection is defined to comprise social insurance and social assistance programs. Social insurance (e.g., unemployment insurance, pensions and healthcare) aims at protecting households from shocks that can adversely impact their incomes and welfare and is typically financed by contributions or payroll taxes. ${ }^{2}$ Social assistance (e.g., universal and targeted transfers) aims at protecting households from poverty and is financed by general government revenue.

For the analysis in this paper, we deviate in one aspect from the coverage of the chart below. We discuss active labor market and training policies under "education spending." Healthcare is discussed jointly with education spending in Chapter III since it is not contribution but tax-funded in Spain.

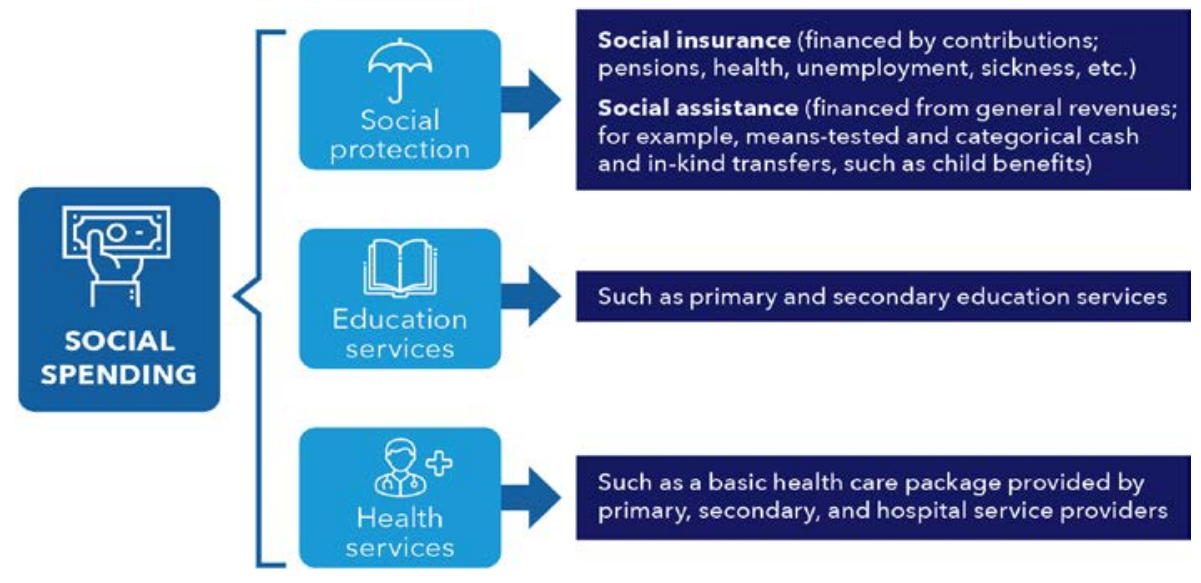

Source: A Strategy for IMF Engagement on Social Spending, IMF (2019).

\footnotetext{
${ }^{1}$ Basic healthcare not covered by health insurance which is of relevance mostly in countries with little health insurance coverage.

${ }^{2}$ Healthcare is not part of social protection definition in Spain since it is tax-funded and universal. But Eurostat includes it in its statistics and it is also part of the framework provided in IMF (2019) if it is contribution-funded which is the case for many European countries.
}

\section{Sustainability, Adequacy, Redistribution and Sustainability OF Social Protection SPENDing}

\section{A. Pensions}

\section{Contributory pensions constitute the largest part of social protection and are considered fairly generous in the regional comparison. They comprise long-term} disability, old age and early retirement, and survivor pensions (Table 1). ${ }^{3}$ There is also a (small) non-contributory pension scheme, aimed at people who are unable join the labor market. Spain's pension spending in percent of GDP is at par with peers and the EU average but the replacement rate of Spanish public pensions, or the average initial benefit as a share of average wage, is considerably higher than the EU28 average (Figure 2). Survival benefits are also much above average. As a result, old-age poverty in Spain is relatively low and pensioners have been well protected from the global financial crisis (IMF, 2017).

\footnotetext{
${ }^{3}$ For the description of pension system's fundamentals see for example IMF, 2017a and EC, $2015 \mathrm{~b}$.
} 


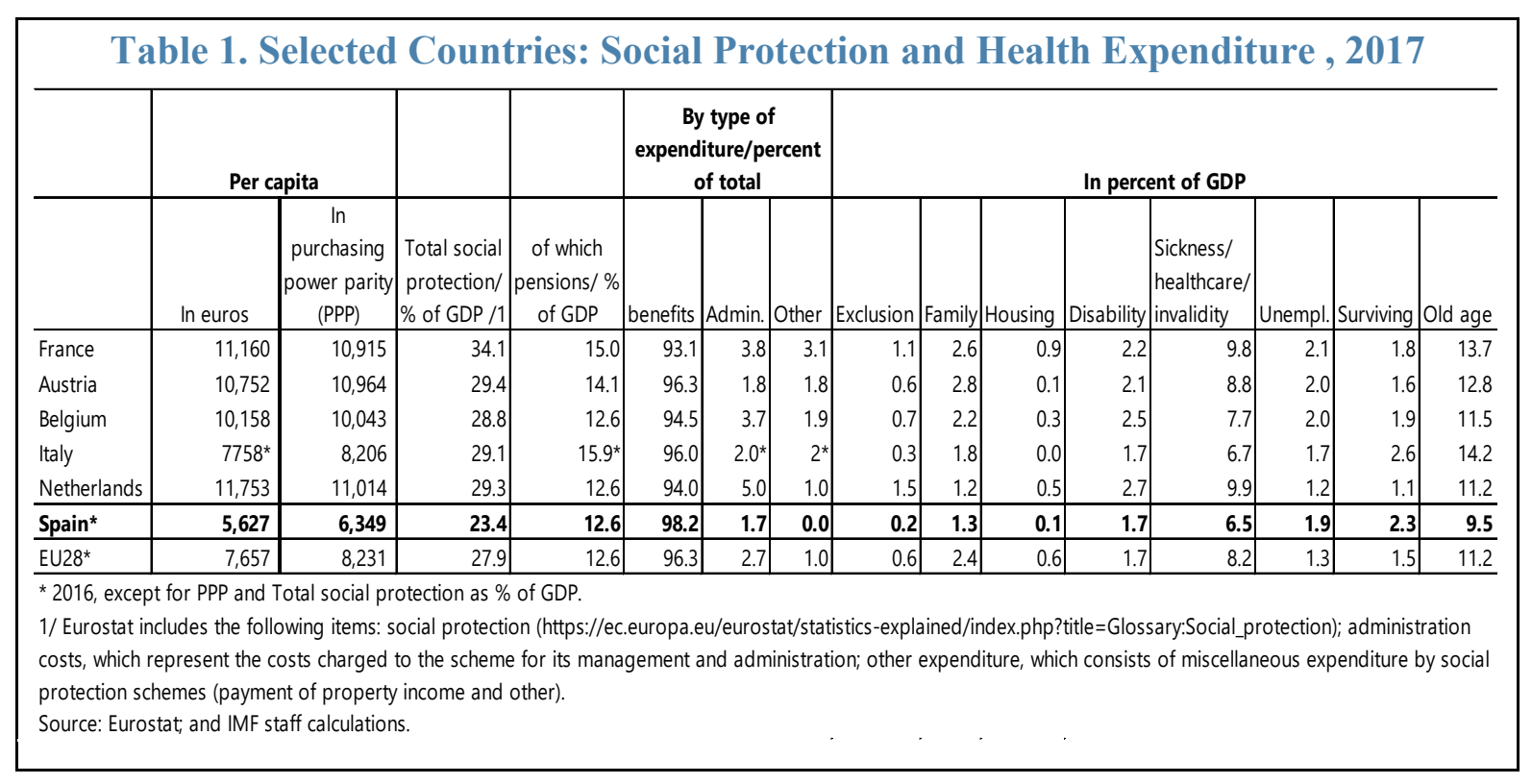

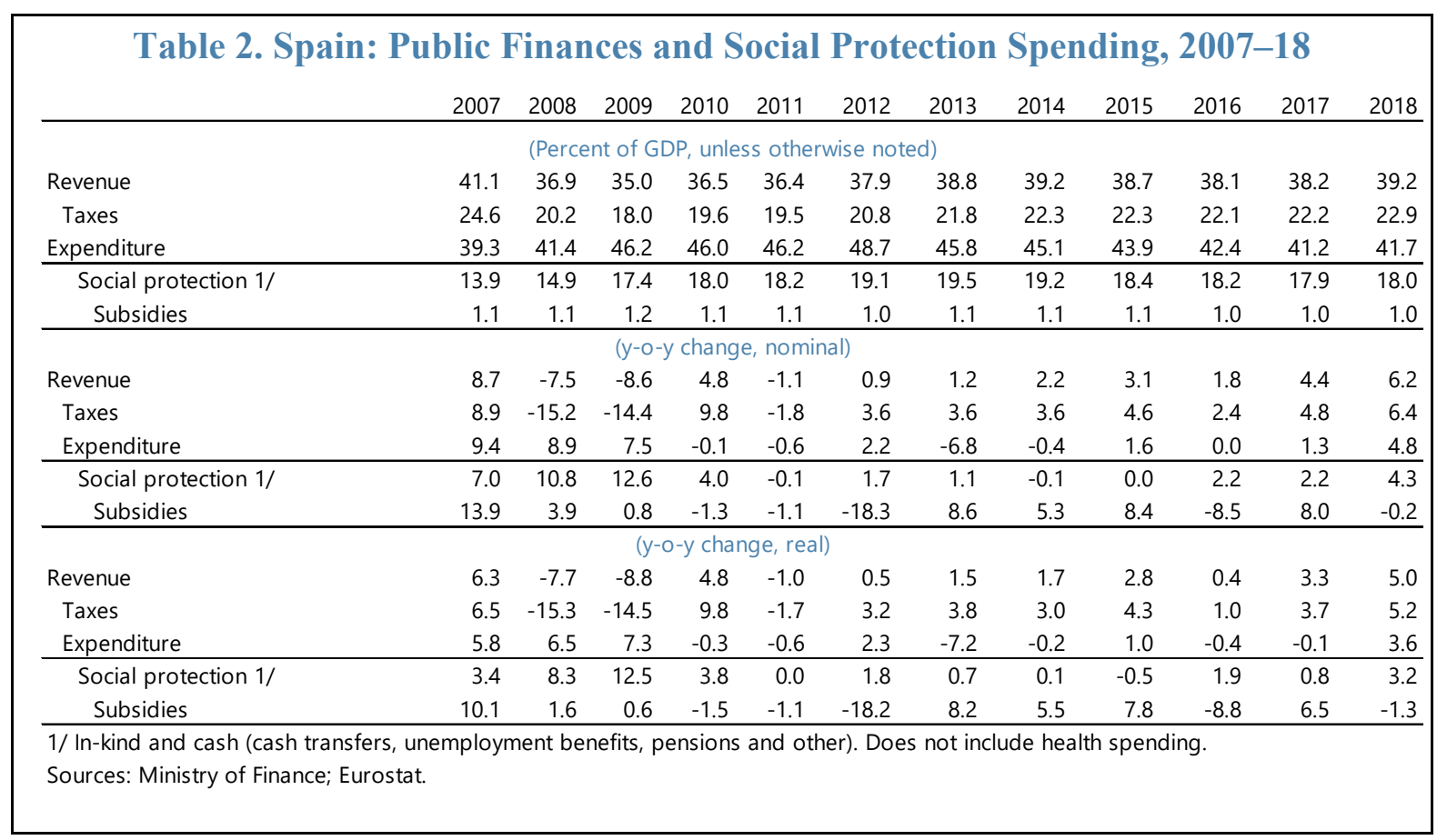

The sustainability of the pension system is at risk unless additional measures are taken. In principle, full implementation of the 2011 and 2013 reforms would keep pension spending broadly in check in response to unfavorable demographics. The 2018 Aging Report, which assumes a full implementation of the reforms, estimates public pension outlays to rise by 1.7 percentage points of GDP by 2050 and fall by 1.5 points through 2070 compared to 2016 . But the 2011/13 reforms would imply a significant reduction in the benefit ratio (that means the average benefit payment in relation to the average wage), which has so far not proven to be socially acceptable. Even though the benefit ratio would stay above the ratio in most other EU countries, social pressure has led to a relinking of pension increases to inflation since 2018 and a delay in implementing a discount ("sustainability") factor for changes in life expectancy. These deviations from the past reforms, if pursued permanently, are estimated to 
result in additional pension spending of about 3-4 percent of GDP by 2050 under current macroeconomic and demographic projections (IMF, 2018; Bank of Spain, 2018). To ensure the sustainability of the pension system, a comprehensive reform package is needed. Specific measures could include: (i) incentivizing longer work lives; (ii) raising revenues without raising the already high contribution rates; and (iii) encouraging supplementary savings (IMF, 2018).

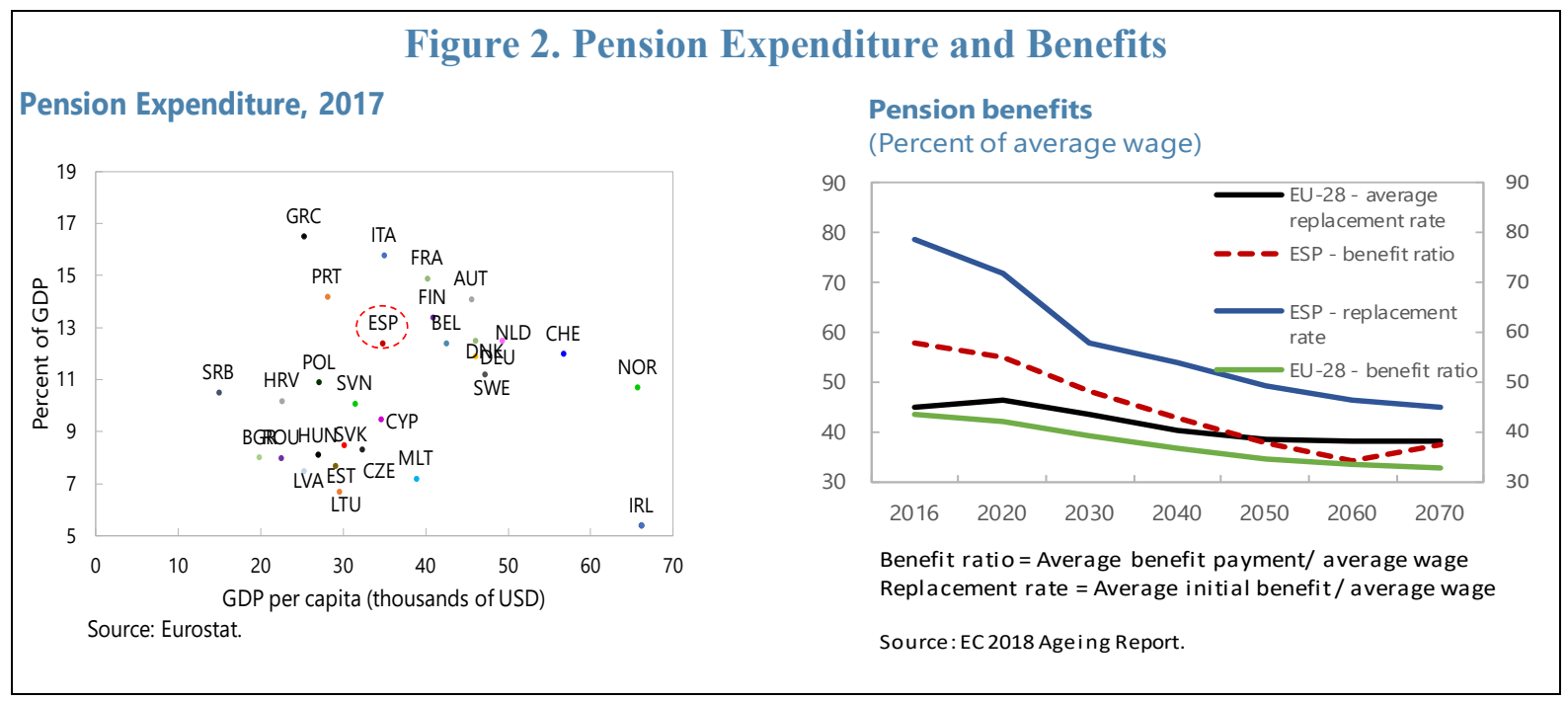

\section{B. Unemployment Protection}

Spending on unemployment in Spain has been consistently elevated given the high level of structural unemployment. The main category is the contributory unemployment benefit (prestación por desempleo). In 2017 it was higher in Spain compared to some advanced economy peers and the EU average, including as a percent of GDP (Table 1). This is largely explained by Spain's still high level of unemployment, which has been the case historically and linked to high structural unemployment (Figure 3). Spending per inhabitant is also above the EU average.

Unemployment protection is viewed as broadly adequate. Levels and duration are considered by some estimates fairly generous (Figure 3; Tatsiramos, 2014; Glassdoor Research, 2016). To receive the contributory unemployment benefit in Spain, a claimant must have contributed to Social Security for a minimum of one year. This contributory period gives the right to receive benefits for 120 days ( 4 months; maximum 24 months), given that a claimant is actively seeking employment. The 2012 reform reduced the amounts drawn after 6 months. Regarding non-contributory benefits, the system consists of several subsidies that cover different situations and have different requirements. Recipients must agree to work with public employment offices to design a personalized job plan to help them find work. Those without access to any of the existent unemployment benefits can apply for the Active Insertion Scheme (renta activa de inserción) and extraordinary unemployment benefits (SED). The latter benefit was introduced in 2018 for long-term unemployed given that displacement is still at a high level in this category. The impact of this program relies on the capacity of the regional public employment services to provide individualized assistance for 
jobseekers, which so far has been uneven by region and statistics are difficult to collect (ILO, 2015; EC, 2017).

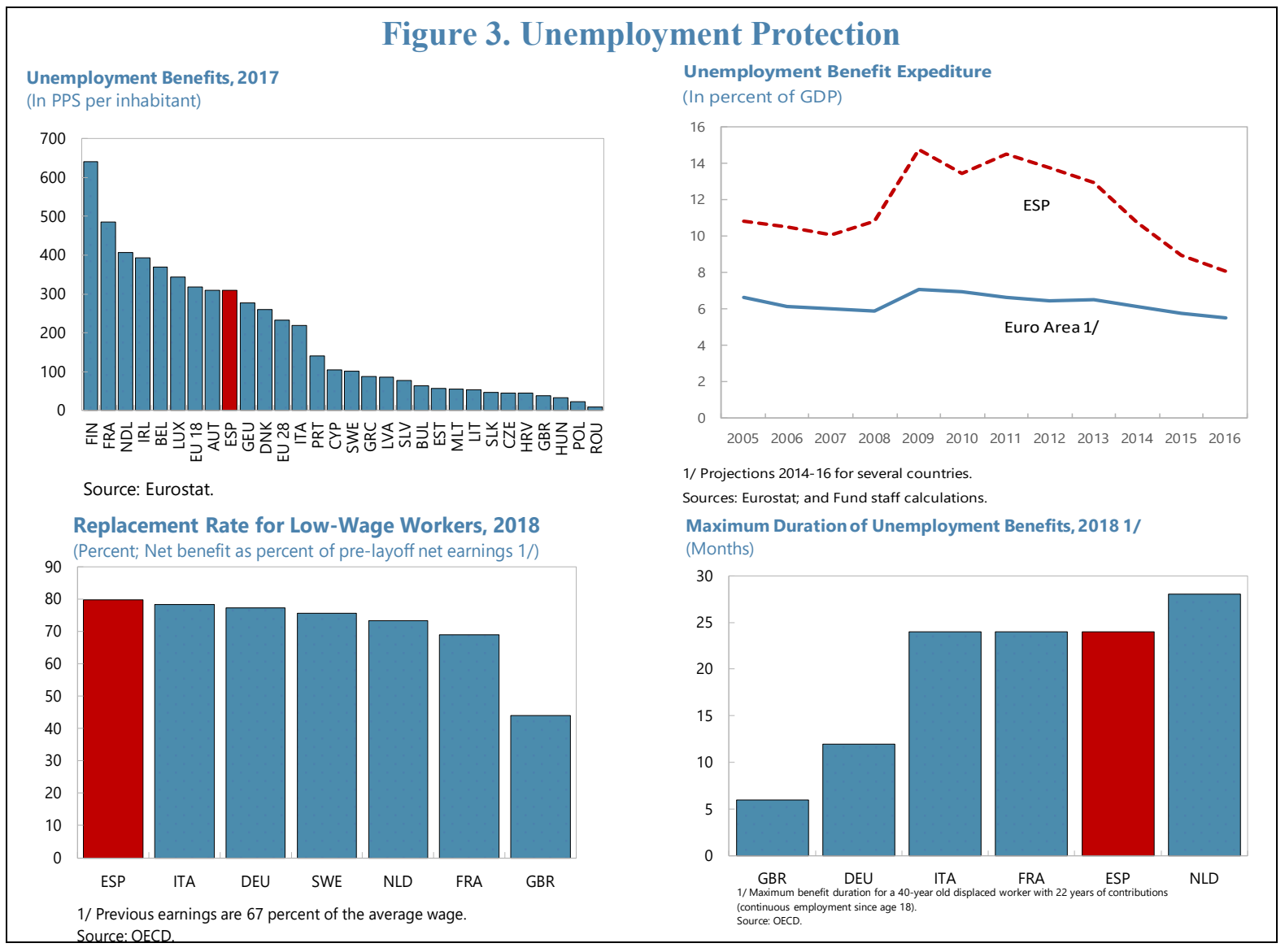

\section{Other Social Assistance}

Other social assistance spending is below the $\mathbf{E U}$ average. Spending on social exclusion, family (including child benefits), and housing stands at about 1.6 percent of GDP, which is quite below the peer average, with spending on housing especially small (Table 1). Family benefits are the main spending item in this category in Spain. ${ }^{4}$ These have trailed advanced peers for quite some time (Figure 4).

\section{Minimum Income Schemes are the main instrument of social assistance aimed at} reducing social exclusion. These are set up as non-contributory cash safety nets supporting people of working age who are not eligible for unemployment benefits, or those whose entitlement to these payments has expired. These include: (i) the non-contributory unemployment support (subsidio de desempleo), at the national level; and (ii) the minimum income benefit, renta mínima de inserción (RMI), at the regional level (Box 2). These

\footnotetext{
${ }^{4}$ Maternity (contributory and non-contributory) and paternity (contributory) leave, benefits for dependent children or foster children, benefits for large families or one-parent or mothers with a disability, and benefits for multiple birth or adoption (EC, 2018c). Assistance is in cash and in-kind.
} 
benefits are means tested and are adjusted to a basic amount defined for a single-person household, supplemented according to the additional household members. ${ }^{5}$ There is considerable variation in both the basic amount and the supplements. Since 2011, pressure from fiscal consolidation as well as from increased demand has led to a series of wideranging adjustments to the minimum income schemes. These initiatives seem to have focused on reducing demand (as well as the number of beneficiaries), while social inclusion objectives appear to have been relegated to the second level of priority (EC, 2015a).

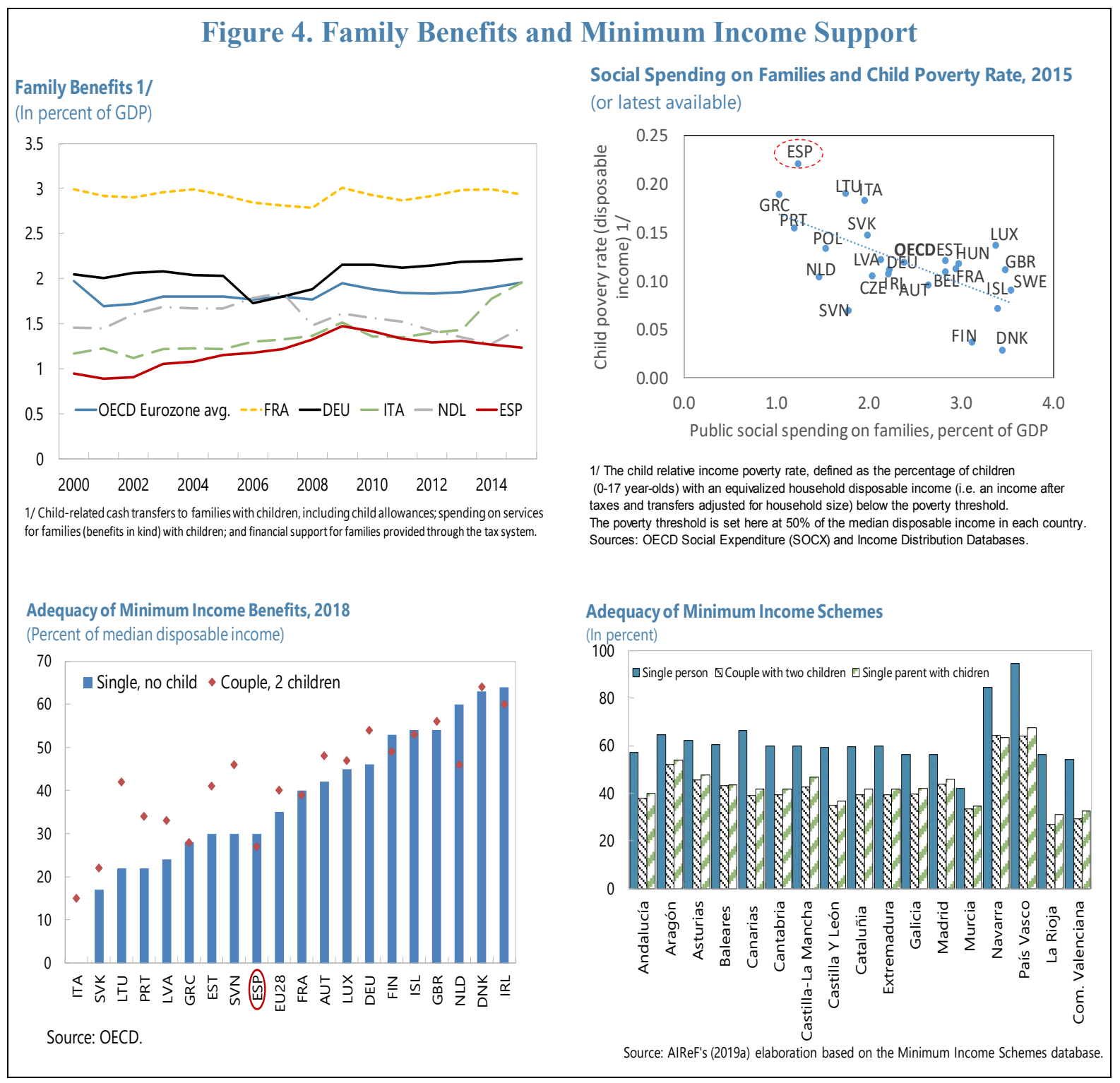

\footnotetext{
${ }^{5}$ Supplements (defined as a percentage of that basic amount) are added for each additional household member. In general terms, these supplements do not take into consideration the specific characteristics of each additional household member (whether they are adults, minors, or disabled). In some regions, supplements are added according to household needs.
} 
Social assistance has not been fully effective in alleviating poverty. As of 2017, over one-quarter of the Spanish population was still at risk of poverty or social exclusion (Figure 5). ${ }^{6}$ Spain has the highest child (0 to 17-year-olds) poverty rate in Western Europe, at 22.1 percent, ahead of Portugal, Italy, and Greece. ${ }^{7,8}$ The majority of the less educated, impoverished and unemployed are concentrated in southern Spain (IMF, 2018a).

\section{Low adequacy and coverage appear to contribute to these subpar outcomes, not least due to a range of policy weaknesses} (Cantó and Ayala, 2014, EC, 2018d). The
Figure 5. At Risk-of-Poverty Rate 1/ (Percent of population)

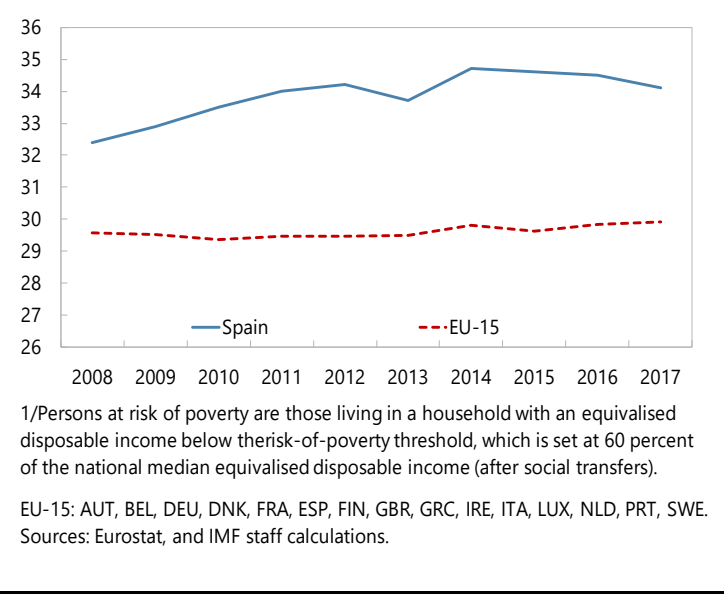
adequacy of minimum income benefits, in particular, indicates shortfalls. It measures the income of jobless relying on guaranteed minimum income benefits relative to the median disposable income in the country. Housing supplements are included, subject to relevant eligibility conditions. In Spain, single (no child) and couple (with two children) households receive minimum assistance that bridges their income to only about 30 percent of the median disposable income (Figure 4). Some other estimates put the b asic minimum income amounts below 40 percent of the national median income, especially for families, with the exceptions of a few autonomous communities (Figure 4). This situation implies that a gap remains between the poverty line and the income levels guaranteed by the minimum income support benefits. While the minimum income schemes target all households in poverty, the actual coverage is much lower than the households in need (EC, 2018d). For example, as of 2014, most of the communities covered only between 1 and 3 percent eligible households (EC, 2015a).

The weaknesses of support schemes in adequacy and coverage could be traced to several reasons. The main issue seems differing levels of sensitivity of minimum income scheme to the size and needs of the household, including different additional benefits for situations of special need (single parenthood, children, disabilities or housing needs) across most regional minimum income schemes. This mainly stems from gaps in coverage by design, including weak benefits for children in need ${ }^{9}$, or inadequate assessment of the support needed to ensure that income is above 40-60 percent of the medium disposable

\footnotetext{
${ }^{6}$ The authorities estimate that the ratio drops to 21.6 percent as of 2017 when including social assistance.

${ }^{7}$ OECD utilizes a threshold of 50 percent of median income, while Eurostat utilized 60 percent which creates discrepancies across countries.

${ }^{8}$ To address child poverty, the amounts of family benefits per child were increased in 2019 (from 341 per year to 588 euros) for families in severe poverty.

${ }^{9}$ Some individuals and households are excluded from benefits because they fail to meet eligibility conditions, even though they may be in need of support.
} 
income. In some instances, households are reluctant to apply for support due to stigma or complex rules (a lack of precision in the definition of the mechanisms and eligibility requirements and complicated administration). Finally, there also could be difficulties with the measurement of income data as it fails to reflect the true amount of resources that households have available to spend (EC, 2013; EC 2015a; AIReF 2019; Funcas 2019). ${ }^{10}$

\section{Box 2. Minimum Income Schemes}

The subsidio de desempleo is received by claimants based on the proportion of hours worked. The underlying requirement is to have some working history, and to be signed up as a job seeker, or working part time. For the latter requirement, there is also some flexibility as beneficiaries can receive the subsidio in the amount of support being reduced proportionally to the number of hours worked or stop receiving it till the job contract ends. Means-testing of these benefits also seem to account for the number of children in the household.

The renta minima de inserción (RMI) is specifically aimed at those with a weak or non-existent employment background, and who are also on low incomes, but there is a large divergence in payouts by region. ${ }^{1}$ Access to RMI varies significantly on a regional level as Autonomous Communities are free to set their own income thresholds, which has resulted in large coverage discrepancies (Cavanillas, 2015; EC, 2014; EC, 2015a; EC, 2019; AIReF, 2019). The differences reflect in part varying costs of living - which are higher in northern regions than in the southern and central ones - and in part political choices on the level of income support (Table). The Autonomous Communities also operate a series of means-tested emergency schemes for people with urgent non-periodical

\begin{tabular}{|c|c|c|}
\hline \multicolumn{3}{|c|}{ Spain: Parameters of RMls 1/ } \\
\hline \multirow[t]{2}{*}{ Autonomos Communities } & Basic 2/ & Duration \\
\hline & euros & months \\
\hline Andalucía & 419.5 & 6 \\
\hline Aragón & 491.0 & 12 \\
\hline Asturias & 443.0 & no limit \\
\hline Baleares & 431.5 & 12/extention possible \\
\hline Canarias & 478.8 & $\max 24$ \\
\hline \multirow[t]{2}{*}{ Cantabria } & 430.3 & \\
\hline & & indefinite as long as conditions are fullfilled \\
\hline Castilla-La Mancha & 446.5 & $24 \max$ \\
\hline \multirow[t]{2}{*}{ Castilla y León } & 430.3 & \\
\hline & & indefinite as long as conditions are fullfilled \\
\hline \multirow[t]{2}{*}{ Cataluña 2/ } & 604.0 & \\
\hline & & indefinite as long as conditions are fullfilled \\
\hline Ceuta & 300.0 & $12 / 60 \max$ \\
\hline Extremadura & 430.3 & 12 \\
\hline Galicia & 403.8 & 12 \\
\hline \multirow[t]{2}{*}{ Madrid } & 400.0 & \\
\hline & & indefinite as long as conditions are fullfilled \\
\hline Melilla & 328 & $12 / 24 \max$ \\
\hline Murcia & 430.3 & 12 \\
\hline Navarra & 610.8 & 12, extention possible \\
\hline País Vasco & 693 & 24, with exceptions \\
\hline La Rioja & 430.27 & duration depends on evaluation \\
\hline Comunidad Valenciana 2/ & 257.8/515.1 & indefinite as long as conditions are fullfilled \\
\hline
\end{tabular}

$1 /$ Schemes and names vary by region.

2/ Includes several schemes/varies by individual or household.

Source: Report on Minimum Income Schemes, 2018.

economic needs (e.g. utility bills, mortgage or other type of loan payments, etc.) that cannot be covered by the Minimum Income scheme (e.g. due to insufficient time of residency in the Autonomous Communities).

${ }^{1}$ In order to establish a connection between RMIs and state unemployment benefits, the 2018 Budget Law established that common criteria for activation should apply to all non-contributory unemployment benefits and clarified that unemployment benefits can be topped up by minimum income schemes (EC, 2019).

\footnotetext{
${ }^{10}$ In addition to means-tested criteria, eligibility conditions for regional minimum income support include age requirements, how long the household has been together, as well as conditions of residency and how long the household has been registered in the municipality. In general terms, these conditions refer to the individual who applies for the benefits, but in certain cases they extend to the household unit (EC 2015a).
} 


\section{Redistribution Impact on Inequality}

Inequality is Spain is higher than in EU peers. The less equal income distribution in Spain is a longer-term phenomenon that was exacerbated during the global financial crisis due to the large job losses (Figures 6 and 7). A job-rich recovery, catalyzed by the 2012 labor market reforms, has reversed some of the negative social economic effects of the crisis, including income distribution (see Stepanyan and Salas, forthcoming) but a significant gap remains compared to other EU countries when measured in terms of the Gini coefficient. ${ }^{11}$

\section{There is less income redistribution in Spain, including via social spending,} against the EU average. The market Gini coefficient is reduced by only 0.18 points once social transfers, taxes, and pensions are considered (which is the disposable income Gini coefficient), (Figure 7). ${ }^{12}$ Taxes and pensions rather than means-tested or nontested transfers (like in Ireland and the United Kingdom) are responsible for about 60 percent of the that reduction. Middleclass households tend to gain in equal proportion or

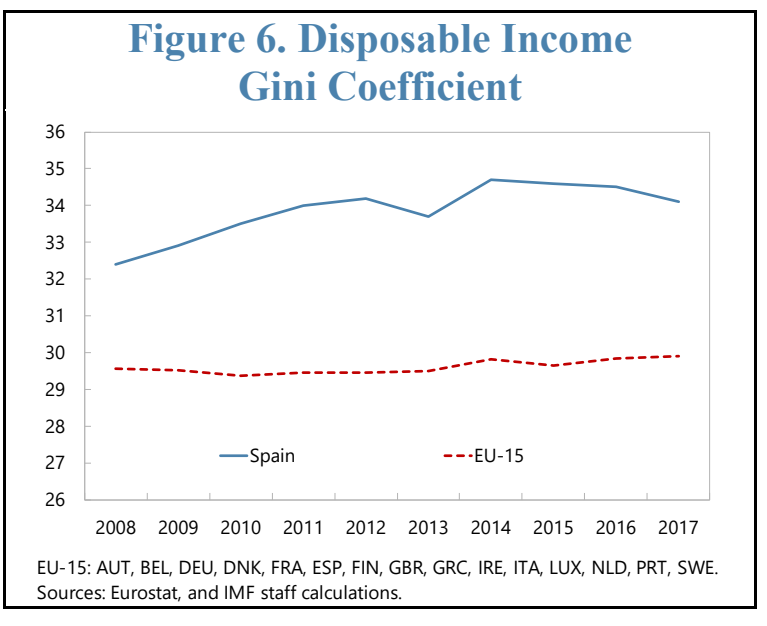
more from redistribution than low income households (Oderkirk, 2017). ${ }^{13}$ The reduction in inequality can also be measured by examining the ratio of the amount of budget resources (as approximated by the ratio of social protection spending-to-GDP) used to achieve one unit of inequality reduction. The index ("Bang for the Buck") shows that Spain is below the EU average redistributive power of social spending by about 15 percent (Figure 7). After fiscal redistribution, disposable income inequality remains high. ${ }^{14}$

\footnotetext{
11 The market income Gini index puts the index at one if there is maximum concentration of income; absolute income equality implies an index of zero.

12 It should be mentioned that not every social spending item has redistributive purposes. In particular, earningsrelated pensions have the aim to maintain the income of the beneficiary.

13 This said, taxes and transfers were relatively effective at reducing market-driven inequalities in those countries hard-hit by the crisis especially in the first phase of the crisis, that is, before the move towards fiscal consolidation measures (OECDb, 2017).

${ }^{14}$ Calculated as the ratio of the Gini index reduction to the share of social protection expenditure in GDP, i.e. the amount of income inequality reduction achieved by 1 percent of GDP of social spending. This "Bang for Buck" concept is also used, for example in IMF (2016) for Ireland. See Herrmann et al. (2008) for assessing the efficiency of state expenditures in reducing poverty rates in EU countries.
} 
Figure 7. Indicators of Redistribution ${ }^{1}$

Taxation and Spending

Contributions to the Reduction in the Gini, 2018

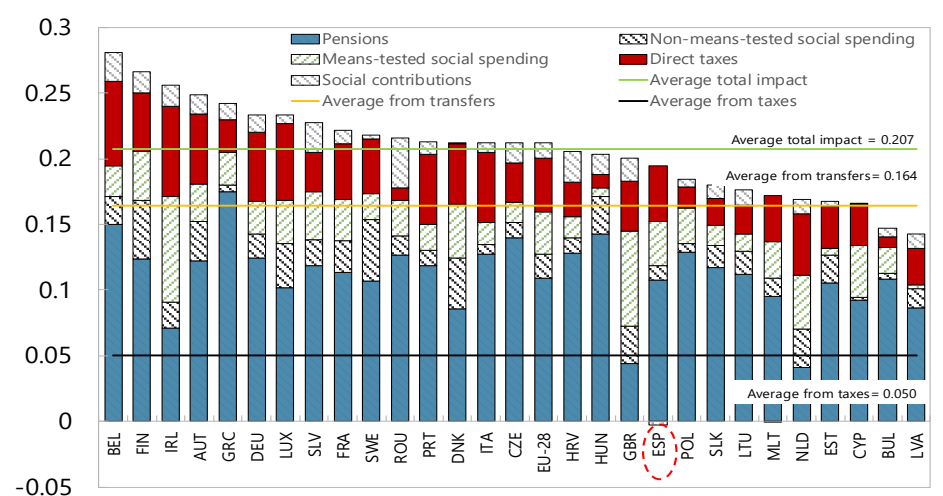

Source: EuroMOD.

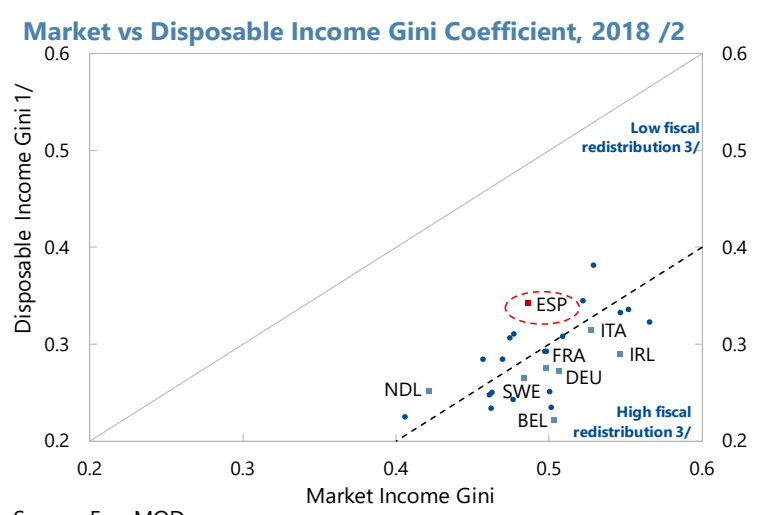

Source: EuroMOD.

Risk of Poverty Rate after Social Transfers and Pensions, 2017

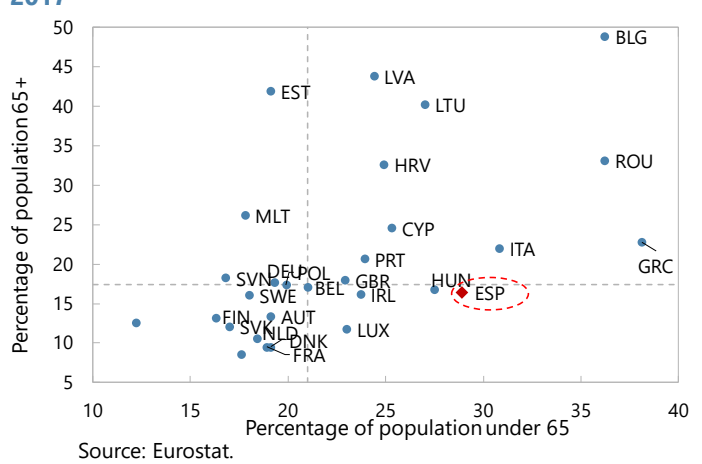

"Bang for the Buck" of Social Spending, 2016

Gini coefficient reduction achieved by 1 percent of GDP of social spending

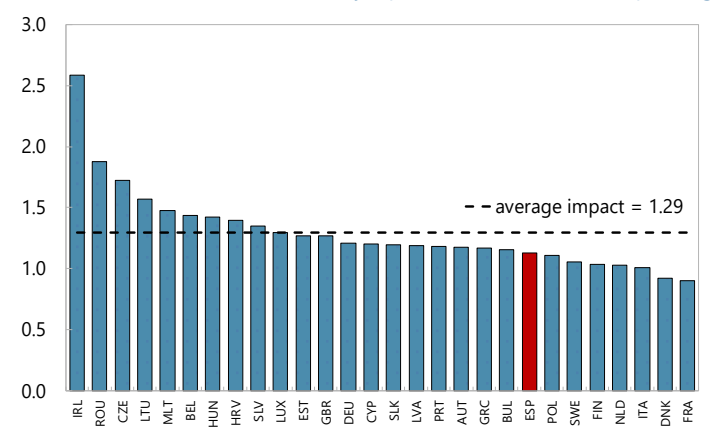

Sources: EuroMOD; and Eurostat.

Change in Relative Poverty Rates via Taxes and Transfers by Age Group, 2016

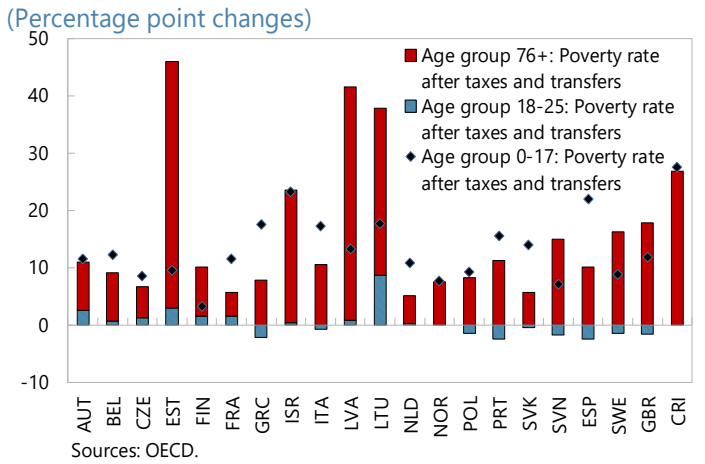

${ }^{1}$ Redistribution is measured by the difference between the Gini coefficient before personal income taxes and transfers (market incomes) and the Gini coefficient after taxes and transfers (disposable incomes) in percent of the Gini coefficient before taxes and transfers. Gini coefficient of zero expresses perfect equality. Calculated by Eurostat using EUROMOD.

${ }^{2}$ Disposable income is the total income of a household, after tax and other deductions, that is available for spending or saving (Eurostat).

${ }^{3}$ Low (high) fiscal redistribution refers to the difference between market and disposable income Gini being less (greater) than 0.2 . 
While the redistributive outcomes for the elderly are better, they create intergenerational issues. As market inequality is stronger among the seniors, this implies that fiscal redistribution focuses on the elderly (Figures 8). This is mainly achieved through public pension spending, which has a larger redistributive impact than non-pension transfers, and also helped the elderly weather the crisis better. The young cohort, on the other hand, is left particularly disadvantaged. As of August 2019, while continuing to improve, 32.2 percent of Spain's youth labor force (16-24 years) was still unemployed, comparing to a 15.4 percent in the Euro Area. While they are eligible for unemployment benefits or minimal social assistance, the system has not been sufficient to prevent wide-spread youth poverty (see section IV).

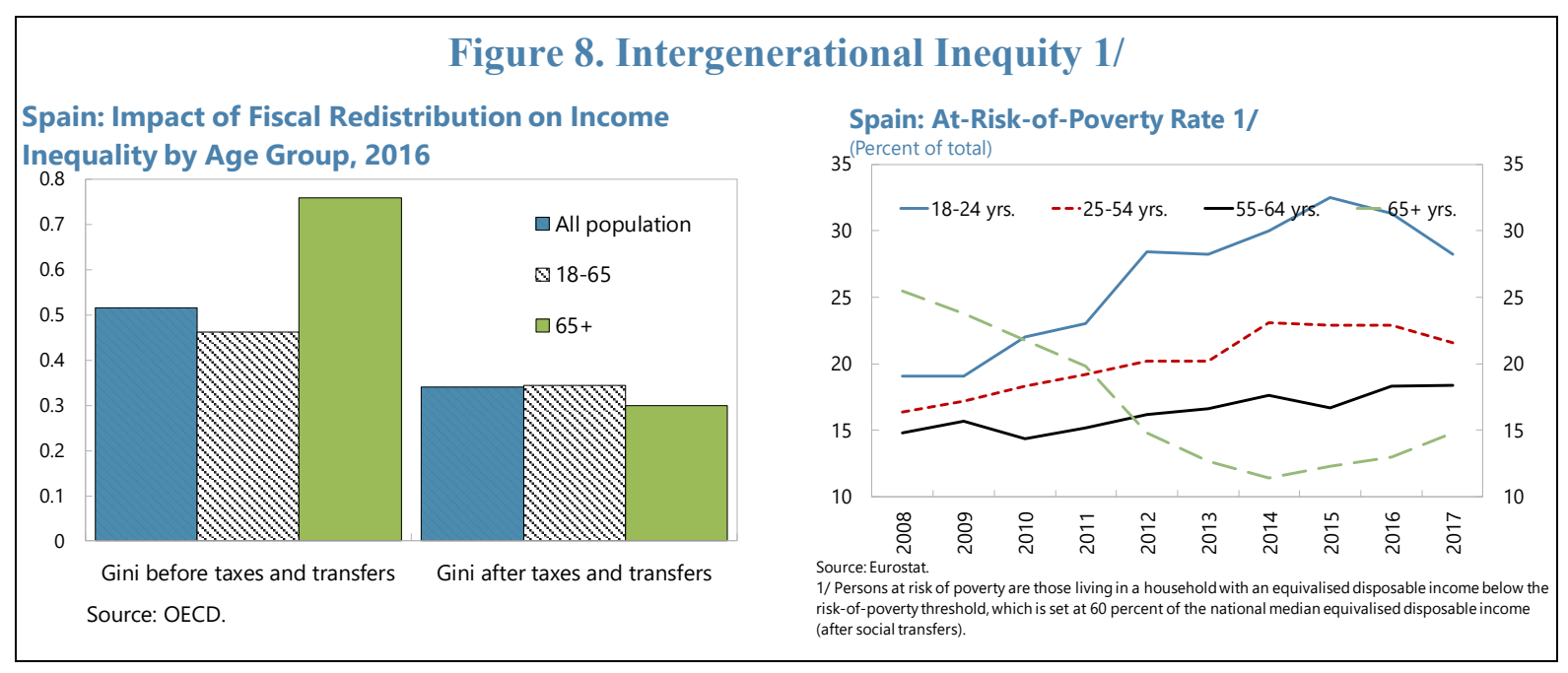

Low means-testing of some benefits seems to contribute to high poverty-at-risk (EC, 2014; OECD 2017b; EC, 2019). ${ }^{15}$ The share of cash family benefits going to the bottom 40 percent of the working age population in Spain is quite low at just over 30 percent, which is significantly below the EU average. It implies that more well-off households receive a substantial portion of the benefits. The gap in targeting reflects the limited use of means-testing of family benefits, in combination with shortcomings in adequacy and coverage (Figure 9).

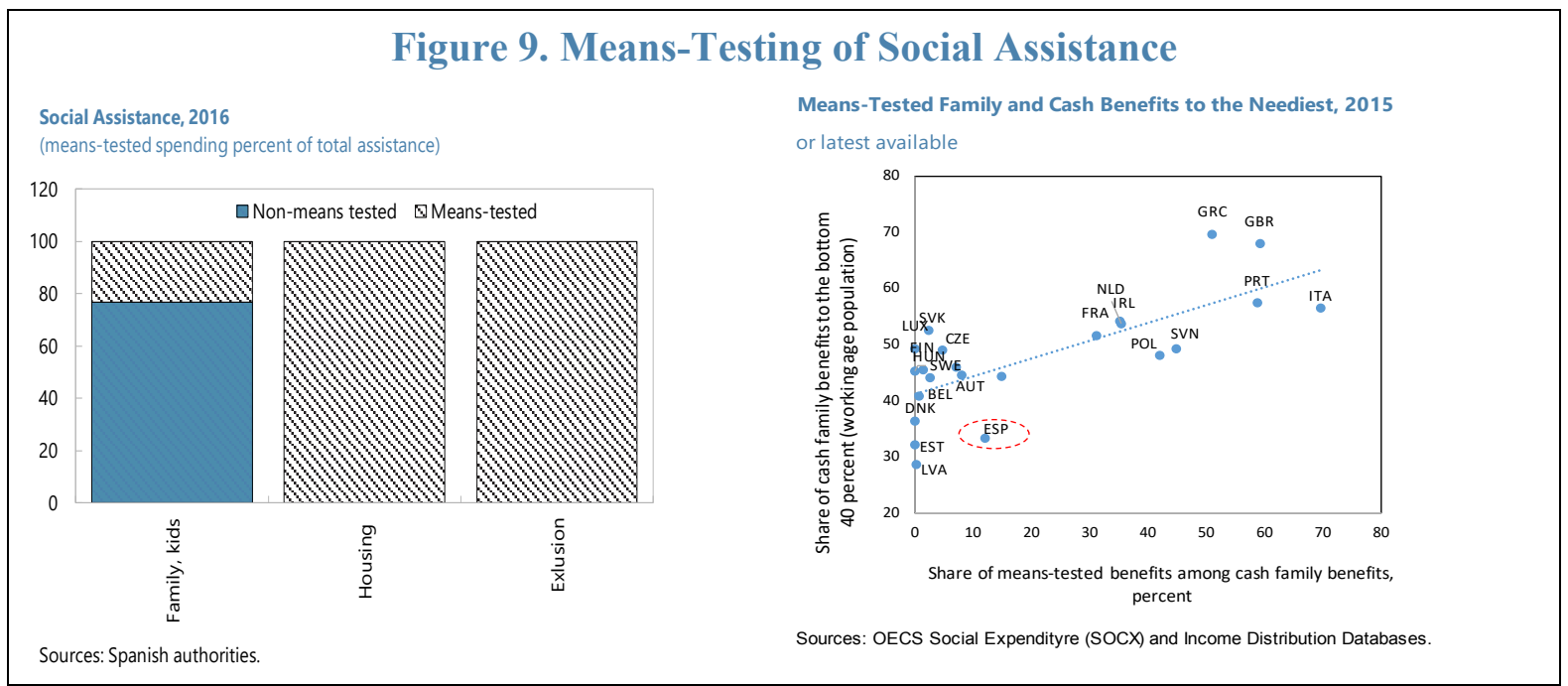

\footnotetext{
${ }^{15}$ Means-tested social benefits refer to benefits where entitlement is explicitly or implicitly conditional on the beneficiary's income/wealth.
} 


\section{EFFICIENCY OF SPENDING ON HEALTH, EdUCATION AND Active Labor Market Policies}

\section{A. Healthcare}

The National Healthcare System in general is equitable and delivers favorable health outcomes. It is highly equitable, as recognized by WHO, in particular for its primary health care network, distributed throughout the territory with easy and universal access, including for obtaining high-cost services. The Spanish health system is generally comparable to most advanced economies providing universal coverage in the following dimensions: population coverage, access equity, technical quality, and economic efficiency (Avanzas et al., 2017; Spain's Health Barometer, 2019). ${ }^{16,17}$ Spain has a high accessibility of primary care as well as high levels of continuity and coordination (EC, 2016).

The healthcare spending is broadly sustainable and spending efficiency is considered to be quite high (Afonso and Kazemi, 2016; IMF, 2016; EC, 2016, 2018). Spain leads Europe in health adjusted life expectancy indicators (74 years) and spends less than its peers (Figure 10). Healthcare spending, which is mostly public and managed at a regional level, represents about 6 percent of GDP, which is below the average of about 8 percent in 2017 . According to the European Commission's 2018 Aging Report, health care spending is expected to face some spending pressure projected at around 0.5 percent of GDP increase by 2070, but this would keep Spain's health care spending still significantly below the EU average. Spain spends a higher share on outpatient than inpatient services than its several European peers, which is often considered to contribute to cost effectiveness and better health outcomes (EC, 2016). Measures taken since 2010 with the objective to reduce costs and raise efficiency are described in Box 3.

\section{Challenges for the healthcare system derive primarily from remaining regional disparities and new issues arising in the provision of health services. Spain performs} better than the EU28 in providing access to healthcare services. Nevertheless, shortages of nurses and general physicians in primary care and long-term care services, especially in some regions, are increasing and further pressures are expected, as almost one third of the doctors are to retire within the next 10 to 15 years (EC, 2019). Growing long-standing disability and chronic conditions because of rapid population ageing also challenge current healthcare delivery (EC, 2016). ${ }^{18}$ Waiting times for surgery, diagnostic procedures and specialized visits remain high, while access to dental care depends in part on families' welfare (BernalDelgado et al., 2018). Public spending on hospitals represents an increasing share of total public spending at the expense of primary care (OECD, 2018a; EC, 2018). The lack of cohesion in electronic systems limits the use of e-health solutions, as well as the coordination and continuity of care, and this greatly varies by region (Causa and Hermansen, 2017). The AIReF review of spending on prescription drugs concluded that there was much room to

\footnotetext{
${ }^{16}$ In July 2018, a Royal Decree-Law was adopted extending health care coverage to undocumented and illegal immigrants.

${ }^{17}$ Almost 70 percent of surveyed believe that the system is adequate but necessitates some changes.

${ }^{18}$ For Spain, more than a doubling of the number of long-term care recipients is projected.
} 
improve governance, procedural aspects related to pricing of medicines, efficiency and equity. In terms of the equity of the system, it was observed that the current medicines copayment model penalizes active low-income workers, in comparison to pensioners with similar incomes and is unequal in its treatment of particularly vulnerable people, such as recipients of minimum income benefits. AIReF's proposals could generate significant savings and efficiency improvements for the system. ${ }^{19}$

\section{Box 3. Recent Measures in the Healthcare Sector}

The reform agenda in the National Health System in recent years has been strongly influenced by the general fiscal constraints that arose during the crisis. Actions since 2010 were targeted at tackling the governance of the system, the breadth of coverage (regulating entitlement conditions), the depth of coverage (categorizing the benefits package), cost-sharing (reformulating the financial participation of patients), drug pricing procedures and the reduction of production costs (for example, decreasing health workforce salaries or prices, reductions in health workforce numbers, centralizing purchasing).

In particular, a Royal Decree Law 20/2012 introduced a series of measures targeting the long-term care system; and a Royal Decree-Law 16/2012, introduced "urgent measures to guarantee the sustainability of the National Health System and improve the quality and security of its benefits". Among others, these measures included an income-based co-payment for pensioners. The new coalition government intends to repeal the Royal Decree-Law 16/2012, especially the provision related to co-payments by vulnerable groups. The implementation of the measures led to the estimated reduction in spending of 11 billion euros over 2012-16 (or about 15 percent of total health spending in 2016), half of which corresponded to excluded pharmaceutical products (2017-2020 Stability Program Update; Figure 3). ${ }^{1}$ Another measure that reduced costs has been the implementation of the Centralized Purchase Platform in 2012 .

With the objective of achieving greater effectiveness and efficiency, over the years, steps have been taken both in the training of healthcare professionals and in the management of the human resources needs in the health sector in the medium and long term, such as the employment stability in the sector.

There are ongoing efforts to consolidate the monitoring process of expenditure on healthcare and pharmaceutical products. ${ }^{2}$ It is expected that the data exchange between the Ministry of Finance and Civil Service and Ministry of Health databases will facilitate better analysis and improve efficiency, together with the active participation of the regional governments. In its 2018 review of prescription medicines, the AIReF estimated that savings could be achieved through the revision of the structure of the Inter-Ministerial Commission for Medicine Prices and a centralized purchase criterion that would allow the public sector to benefit from the discounts currently available to pharmacies. On the demand side, it recommended to follow the best prescription practices found in stewardship and control protocols to maximize savings across the regional governments.

${ }^{1}$ The government signed agreements with Farmaindustria to limit the growth of pharmaceutical expenditure, which was extended in 2019 (2019-22 Stability Report).

${ }^{2}$ The 2019 AIReF review concentrated on hospital-related expenditure, in particular pharmaceuticals, within the national health system.

Sources: Bernal-Delgado et al. (2018); EC 2017; 2019-2022 Stability Program Update, Coalition agreement (2020).

\footnotetext{
${ }^{19}$ When the impact of each proposal is evaluated in isolation, the total estimated savings sum up to 1.9 billion euros by 2022. But as some of the proposals would reduce the same aspects of inefficiency; their joint application would result in more modest savings.
} 


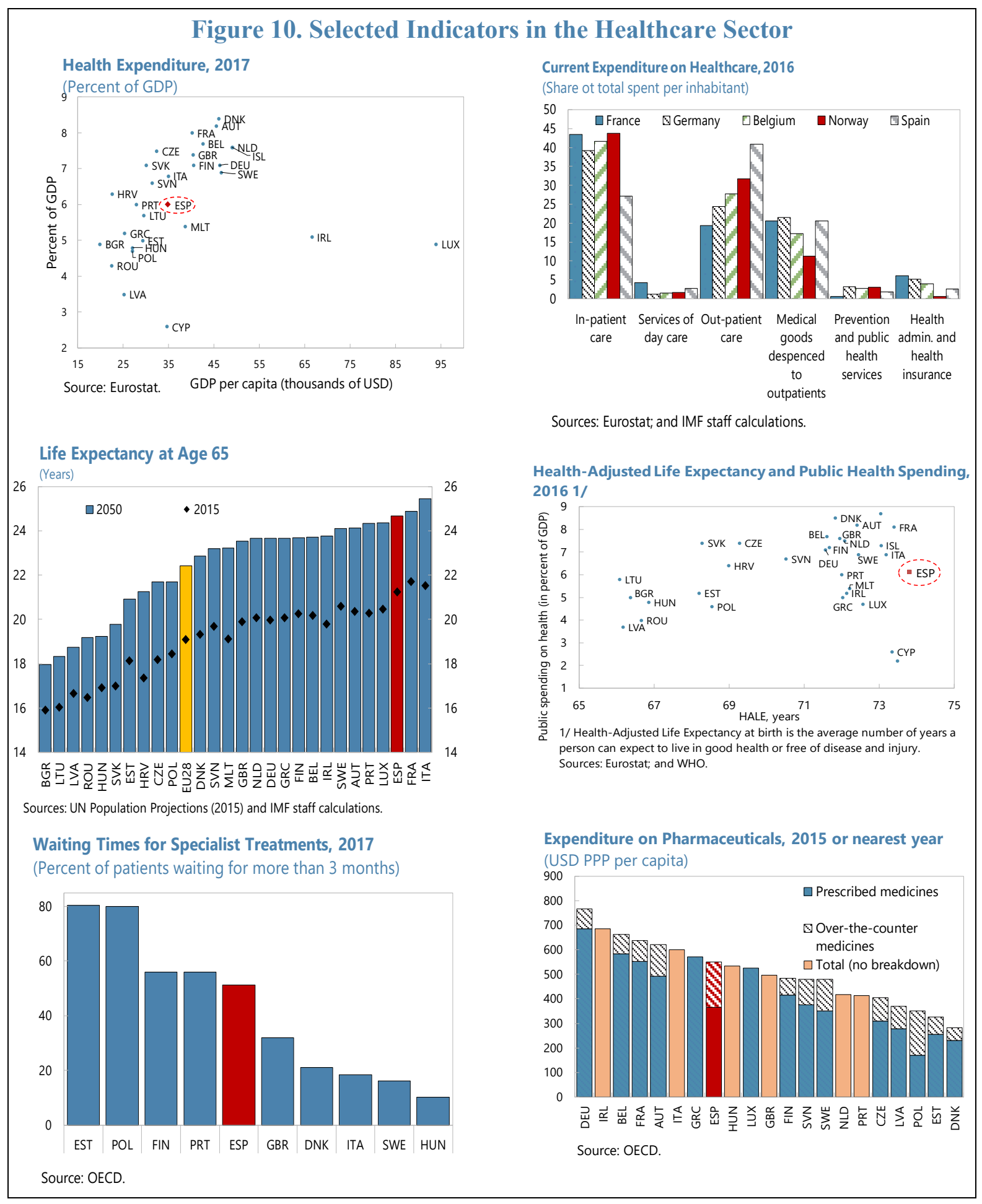

CInternational Monetary Fund. Not for Redistribution 


\section{B. Education and Training}

Education and training are arguably the most important factors to ensure equality of opportunities as they deliver clear returns in terms of income. For individuals, education promotes employment, earnings, health, and poverty reduction, while for the society as whole it drives long-term economic growth, spurs innovation, strengthens institutions, and fosters social cohesion (World Bank, 2018). Debates on education commonly focus on the need for more spending, but, as in other areas of social spending, efficiency and targeting (in case of active labor market policies) are an important part to achieving better outcomes.

Education spending in Spain is relatively low. Total public expenditure on education is less than the EU average, and it declined from 4.4 to 3.9 percent of GDP over 2011-2017, against the EU's 4.6 percent (despite a broadly stable share of spending for those below 25 years of age). ${ }^{20}$ Cumulative public spending per student as of 2015 was below most of the advanced EU economies. According to the 2018 Aging Report, education spending is projected to rise by 0.4 percent of GDP by 2050 and then decline by 0.2 percentage points to 3.9 percent by 2070 .

\section{Education outcomes have generally}

lagged EU peers. While after years of underperformance PISA scores improved in 2015, reaching OECD averages in all three core areas, they fell or stagnated in 2018 testing, especially in sciences (Figure 12). ${ }^{21}$ Barriers to intergenerational mobility are high (Figure 11). There has been no upward intergenerational mobility in educational attainment for 55 percent of the children of low educated parents who also have not attained an upper secondary education (OECD, 2018d and 2018e). This is also reflected in the large percentage of

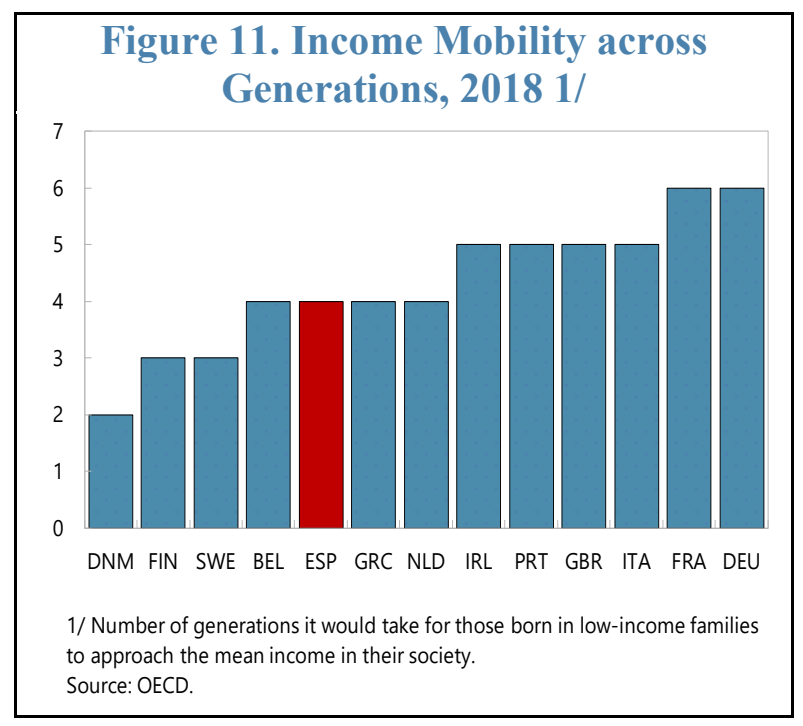
young adults without an upper secondary education. This accounts for 34 percent in Spain compared to 15 percent on average across OECD countries, in spite of a significant increase by 25 percentage points in upper secondary first-time graduation rate between 2005 and 2016. Despite significant improvements over the past years, the early school leaving rate remains among the highest in the OECD, at 18.3 percent in 2017. New tertiary graduates still face challenges finding suitable work. The gap between the unemployment rate of those with tertiary education (where attainment targets are being met) and less than upper secondary education, at around 14 percent, is higher than the EU average of 10 percent (OECD, 2018a). The share of young people neither in employment nor in education or training (NEET) was at

\footnotetext{
${ }^{20}$ In 2012, the central government also approved the Decree-law 14/2012 on urgent measures to rationalize education spending.

${ }^{21}$ See Afonso, A. and M. Kazemi, 2016; IMF, 2015/2016 for Data Envelopment Analysis for benchmarking education outcomes.
} 
around 15 percent in 2017 (Figure 12). Participation rates in education and training are low, also resulting in subpar basic and advanced digital skills levels. Regional disparities in educational outcomes persist, for instance, in PISA scores, early school leaving rates, grade repetition, and performance (EC, 2018d and 2019). One positive indicator is Spain's very high early childhood education enrolment rate: 96 percent of children aged 3 to 6 years were in education in 2015 compared to 76 percent on average across OECD countries (OECD, 2018c).

The expenditure on active labor market policies in Spain is also relatively low and not particularly effective (Figure 12). In Spain, the active labor market policies (ALMPs) include programs for labor integration, training, job rotation and job sharing, employment incentives, supported employment and rehabilitation, direct job creation and start-up incentives. In terms of participation, the main component of ALMPs are training programs (ILO, 2015). The evidence so far indicates that spending on ALMP measures and labor market services is low relative to the number of unemployed persons and is diversified across a large number of programs. In general, the programs are not considered to be effective in matching cohorts with necessary skills, especially the long-term unemployed, low-skilled and youth, and are not well coordinated or designed to foster employability, although there are some few positive experiences (ILO, 2015; IMF, 2017b and 2018b; EC, 2019). Moreover, ALMPs have limited participation rates, the Public Employment Services face capacity constraints to offer individualized support, several policies are not appropriately targeted, and evaluation mechanisms are uncommon.

Education reforms, which have been piecemeal, have been paused altogether since 2016. While a state ministry carries an overall mandate, the 17 Autonomous Communities make most of the decisions regarding their own education systems, making coordination challenging. Political disagreements, including on the level of spending, stalled the negotiations on a needed broad-ranging education reform. Some recent initiatives do seek to improve the matching between initial vocational education and training and labor market needs through a higher involvement of the business sector and a review of the qualifications framework (OECD, 2018c). The government also approved measures in coordination with the regions, social partners and other stakeholders to further develop and upgrade the dual vocational education and training system, promote work-based learning and raise the attractiveness of the system. One important issue that is yet to be addressed is improving the quality of teaching (OECD, 2014). ${ }^{22,23}$

\footnotetext{
${ }^{22}$ The 2013 Organic Law on the Improvement of the Quality of Education (LOMCE) did not address the issue of teachers' quality. According to OECD (2014), 36 percent of teachers never received formal appraisal.

23 Teachers in Spain are paid at or slightly above the OECD average depending on the years of experience (2017). The average class size is slightly below the OECD average (2016).
} 
Figure 12. Selected Education and Active Labor Market Policy Indicators

Public Education Spending, 2017

(Percent of GDP)

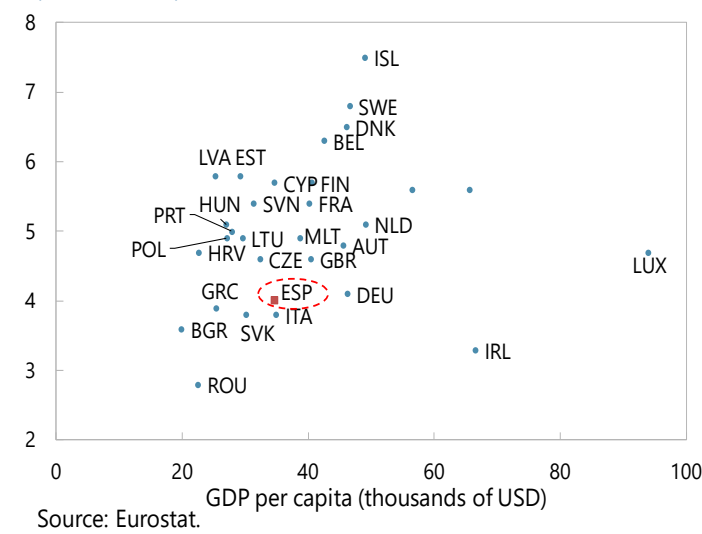

NEET Rates, 2017

(Percent of total 15-24 population neither in employment, nor in education or training)

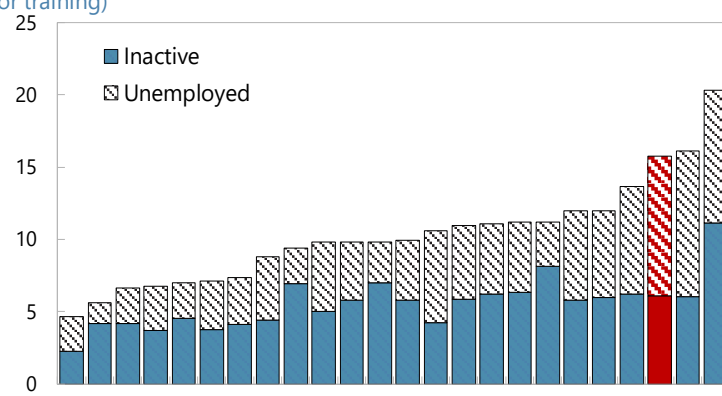

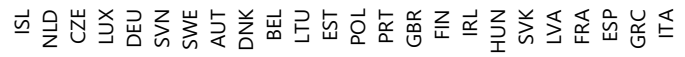

Source: $\mathrm{OECD}$.

Active Labor Market Policies: Expenditure on Training, 2016

(PPS per person wanting to work)

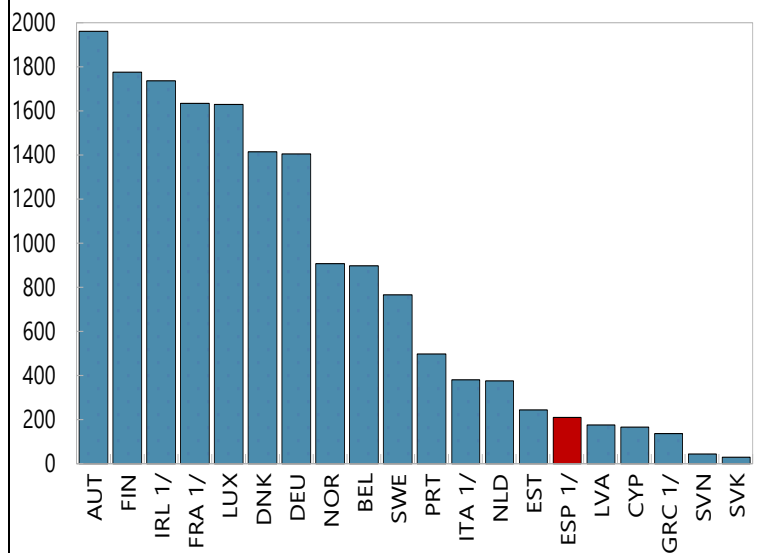

Source: Eurostat.

$1 / 2015$ value is used.
Annual Spending on Primary and Secondary Education per Student (2016 or latest year) and Average PISA scores (2018)

(Spending in PPP US dollars) /1

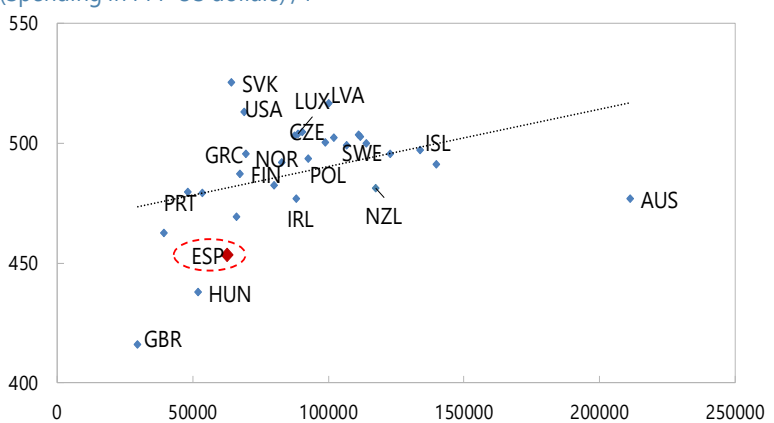

1 / Cumulative expenditure on private and private educational institutions per full-time student between age 6 and 15).

Source: OECD.

Participation Rate in Education and Training, 2018 1/

(Percent, 25-64 years)

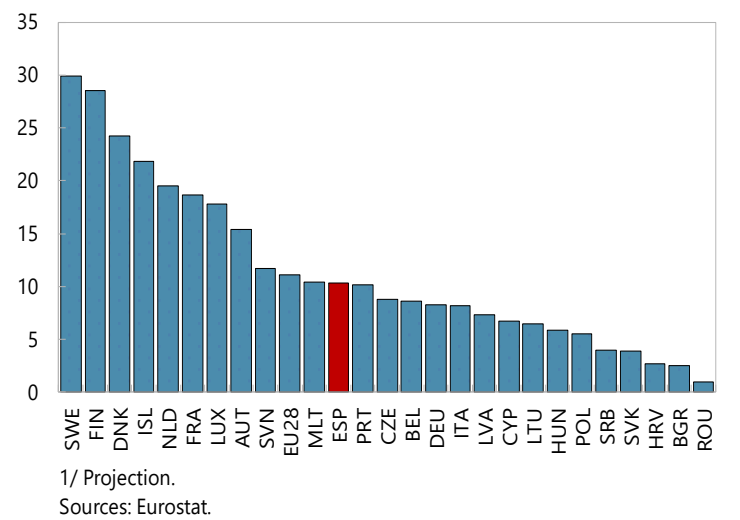

Expenditure on Labor Market Policies and Unemployment Rate, 2015 1/ (Percent of GDP)

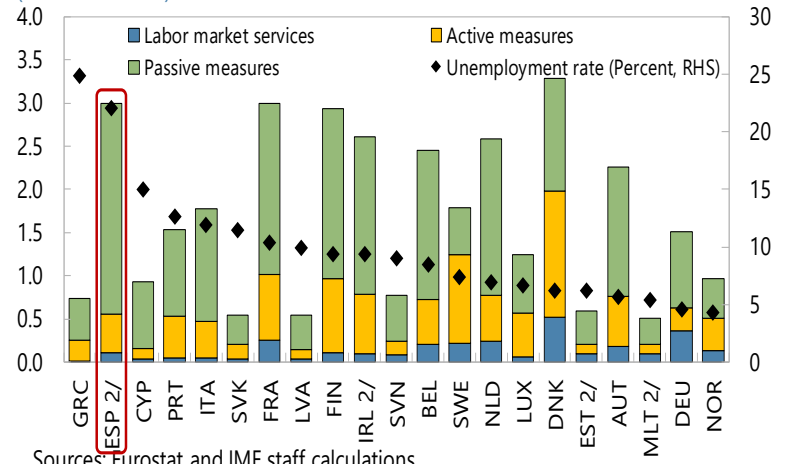

Sources: Eurostat and IMF staff calculations.

1/ Labor market services refer to LMP category 1, active measures to categories 2-7 and passive measures to categories 8-9 (Out-of-work income maintenance and support, early retirement).

2/ 2014 value is used 


\section{Takeaways and Policy Recommendations}

Social spending in Spain is below the peer average in several categories and in many aspects is not achieving effective outcomes. The bright spot is the generally wellfunctioning healthcare system, which provides equity in access and delivers favorable outcomes at efficient spending levels. The contributory pension system has so far offered high replacement ratios at reasonable pension spending-to-GDP ratio, resulting in low oldage poverty. But in light of population aging, maintaining such pension benefits without comprehensive reforms is not sustainable and would come at the expense of the already disadvantaged younger generation. Moreover, the elevated spending on unemployment protection reflects the high level of structural unemployment, indicative of lingering skills mismatches in the labor market and poorly targeted education and training programs. The least social assistance is devoted to the most vulnerable, which are children and low-income households.

In particular, social assistance programs do not deliver fully on their objectives. There are gaps in adequacy and coverage not least due to inefficiencies in the administrative systems, low income thresholds as well as means testing, and a lack of coordination. These weaknesses stand in a way of reducing the levels of risks of poverty, income inequality and exclusion.

Given the high level of decentralization, a first step toward improving the effectiveness of social assistance would be a more coordinated approach. A good start would be reopening a dialogue on the necessary reforms and improving communication between the stakeholders. Despite the attempted reforms since 2000s, social interventions remain largely fragmented along single objective dimensions (employment, housing, etc.) and lack a unified, coherent approach (EC 2015a). There is generally no single point of contact or onestop shop to coordinate income support, social and unemployment services in order to offer a joint response to the challenges derived from lack of employment or other situations that push people towards social exclusion. ${ }^{24}$ Reducing the overlapping benefits and improving their mobility across regions would also make the system more efficient and may also facilitate the participation in the labor market (Fournier and Johansson, 2016). ${ }^{25}$ The introduction of the Universal Social Card that came into force in October 2018 could help collect information on all benefits received by individuals from the national and regional governments (see below on coordination of ALMP).

On a more granular level, the effectiveness could be improved along several lines laid out below (see also Funcas, 2019; EC, 2019; AIReF, 2019). Any strategy that involves expanding social spending would need to be sustainably financed, in particular in the context

\footnotetext{
${ }^{24}$ In the early 2000s, a set of regional plans for social inclusion explicitly mentioned the objective of coordinating resources and strategies to achieve that goal but few were implemented. More recently, some regions have implemented certain coordination practices (drafting protocols, establishing multidisciplinary teams, creating joint programs to intervene with vulnerable groups) among different services (RodriguezCabrero et al., 2015).

${ }^{25}$ Six regions established the possibility to conclude agreements with other regions to ensure the transfer of rights in their legislation, but so far only two regions started to negotiate such an agreement (EC, 2019).
} 
of Spain's elevated public debt. It should not crowd out other spending (e.g. physical infrastructure) that is also crucial for promoting inclusive growth nor create significant distortions (IMF, 2019).

- Improving access to assistance to the families in need, calibrating better the sustainable income levels, increasing the means-testing of some existing benefits (e.g. daycare, scholarships), increasing funding of selected programs, and improving access to programs could lead to improvements in "at risk" poverty indicators and inclusion. In this context, the proposal by AIReF (2019a) on the design of a basic social benefit and its medium-term financing options are worth a close examination but this would have to go hand-in-hand with estimating the adequacy, coverage and efficiency of the existing assistance programs. There is also a need to reduce the complexity of the administrative processes and the bureaucratic hurdles to increase the participation in the existing programs.

- Education, training and active labor market policies need to ensure better matching with market needs. Reducing barriers to intergenerational mobility, regional disparities, and skill matches are critical for providing greater equality of opportunities. In this respect, the recent initiatives on new training and geographical mobility initiatives and plans to introduce a teacher appraisal system will require appropriate funding to support the implementation and monitoring of the progress. Moreover, well-targeted and costeffective vocational training and active labor market policies as well as improved apprenticeship could be helpful in bridging unemployment and opportunities (McGowan and Andrews, 2015; IMF, 2017b). To that end, for example AIReF suggested ensuring that the information collected on active labor market policies, coordinated by the State Public Employment Service, should be more standardized in terms of training and careers to facilitate the evaluation of the policies that are working properly. There is also room to consolidate the vast amount of active labor market policies, with low participation rates and little funding, and instead expand on the most promising exiting programs (IMF, 2018a, 2018b). Further coordination between stakeholders is needed to ensure that all regional models comply with key standards for dual vocational education and training, and data is publicly available and consistently coded cross regions to better evaluate the success of policies (ILO, 2015; OECD, 2018a; EC, 2019).

- Healthcare policies should be targeted at further reducing regional disparities and addressing emerging challenges. Following the government's objective, the health cohesion instrument of the National Health System should be improved, and resources allocated to the coordination of the system should be strengthened. With a view to reducing health inequalities, the European Commission (2019) recommended, for example, to develop and promote interoperable e-government and e-services, in particular in remote regions, and including joint provision of services in border areas. It also called for more investments in infrastructure targeted at strengthening primary care and integrated care. There is also room to widen the spectrum of policy tools effectively used to ensure fiscal sustainability of health care spending; and improve cooperation between 
budgeting officials and those in charge of healthcare (EC, 2016). ${ }^{26}$ AIReF sees opportunities for improvement in the system in terms of governance, procedural aspects, efficiency and equity in prescription drug pricing, and giving more weight to Autonomous Communities in the decision-making process.

\section{More effective social spending cannot be the only tool to raise living standards and}

reduce inequality. Efforts also need to be directed toward making the labor market more inclusive, in particular by addressing the high share of temporary employment, which is associated with high employment volatility, low productivity growth and rising income inequality. The large gap in the dismissal costs between permanent and temporary jobs remains the root cause for employers offering too few open-ended contracts. The best results for shifting to a higher share of permanent jobs without necessarily raising the overall dismissal costs for employers and lowering the employment protection for most workers can be expected from combining a single open-ended contract with a separation fund (IMF, 2018a).

\footnotetext{
${ }^{26}$ Policy tools, inter alia, include improving reimbursement mechanisms, enhancing provider competition, defining strategic objectives of the health sector and using eHealth tools. Currently Spain is assessed to be using only 3 out of 17 suggested tools.
} 


\section{REFERENCES}

Afonso, A. and M. Kazemi, 2016, “Assessing Public Spending Efficiency in 20 OECD Countries", Lisbon School of Economics and Management, WP12/2016/DE/UECE.

Avanzas, P., Pascual, I., and C. Moris, 2017, “The Great Challenge of the Public Health System in Spain", Journal of Thoracic Disease, 9 (Suppl 6): S430-S433.

Avram, S., Figari, F., Leventi, C., Levy, H., Navicke, J., Matsaganis, M., Militaru, E., Paulus, A., Rastringina,O. and H. Sutherland, 2013, "The Distributional Effects of Fiscal Consolidation in Nine Countries," EUROMOD Working Paper No. EM 2/13 (Essex: Essex University Institute of Social \& Economic Research).

Bank of Spain, 2018, "Recent Pension System Measures: Analysis of Impact on Public Finances," Box 6 in Economic Bulletin 4/2018.

Bernal-Delgado, E., García-Armesto S., Oliva J., Sánchez Martínez FI., Repullo JR., Peña Longobardo LM., Ridao-López M., C. Hernández-Quevedo, 2018, "Spain Health System Review 2018”, The European Observatory on Health Systems and Policies, Health Systems in Transition, Vol. 20, No. 2.

Cantó, O. and L.Ayala, 2014, "Políticas Públicas para Reducir la Pobreza Infantil en España: Análisis de Impacto". Madrid: UNICEF. http://goo.gl/IDd0Zh

Causa, O. and M. Hermansen, 2017, "Income Redistribution Through Taxes and Transfers across OECD Countries”, OECD, Economics Department Working Papers, No. 1453.

Cavanillas, D., 2015, “Spain's Welfare System: An Overview”, Policy in Practice, March 24. Available at http://policyinpractice.co.uk/spains-welfare-system-an-overview/.

Chen, T., Hallaert, J.J., Pitt, A., Qu, H., Queyranne, M., Rhee, A., Shabunina, A., Vandenbussche, J., and I. Yackovlev, 2018, "Inequality and Poverty Across Generations in the European Union”, Staff Discussion Note No. 18/01, Washington, International Monetary Fund.

European Commission (EC), 2013, The Coverage Rate of Social Benefits”, Research Note 9/13. ,2014, “European Minimum Income Network”, Country Report: Spain. ,2015a, "ESPN Thematic Report on minimum income schemes: Spain.” ,2015b, Spain Country Fiche: Impact of Ageing Populations on Pensions, Ageing Working Group.

, 2016, "Joint Report on Health Care and Long-Term Care Systems and Fiscal Sustainability”, Volume 1, Institutional Paper 031. , 2017, Country Report: Spain. ,2018a, The 2018 Ageing Report. 
, 2018b, Pension Adequacy Report.

, 2018c, Your Social Security Rights in Spain.

, 2018d, Country Report: Spain.

, 2019, Country Report: Spain.

Fournier, J-M. and A.. Johansson, 2016, "The Effect of the Size and the Mix of Public Spending on Growth and Inequality", OECD, Economics Department Working Papers No. 1344.

Funcas, 2019, "Pobreza y rentas mínimas”, Panorama Social, Primer trimester.

Gorjón Garcia, L., and A. Villar, 2019, "The Minimum Income Scheme as a Poverty Reduction Mechanism: The Case of the Basque Country", Fedea, Estudios sobre la Economía Española, 2019/10.

Glassdoor Research Report "Which Countries in Europe Offer the Fairest Paid Leave and Unemployment?", 2016, at https://www.glassdoor.co.uk/blog/social-benefits-europeisnt-britain/

Gómez, F. and F. H. Buendía, 2016, "Crisis and Welfare Society in Spain”, International Journal of Humanities and Social Science Invention; Volume 5, Issue 8, August 2016, pages $32-39$.

Herrmann, P; Tausch, A.; Heshmati, A.; C..Bajalan (2008), "Efficiency and Effectiveness of Social Spending", IZA Discussion Papers, No. 3482,Institute for the Study of Labor (IZA), Bonn, http://nbn-resolving.de/urn:nbn:de:101:1-2008052722

Independent Authority for Fiscal Responsibility (AIReF), 2019, Spending Review (https://www.airef.es/es/spending-review/).

,2019a, "The Programs of Minimum Incomes in Spain".

International Monetary Fund, 2014, "Fiscal Policy and Income Inequality", Policy Paper, Washington.

, 2015, "The Efficiency of Public Spending in Health and Education in Hungary", Country Report No. 15/93, Washington.

, 2016, Public Expenditure Efficiency in Ireland, Country Report No. 16/257, Washington.

, 2017a, "The Spanish Pension System-Challenges Beyond Financial Stability”, Country Report No. 16/257, Washington.

, 2017b, Spain: 2017 Article IV Consultation Staff Report, Country Report No. 17/319, Washington. 
, 2018a, Spain: 2018 Article IV Consultation Staff Report, Country Report No. 18/330, Washington.

,2018b, "Differences in Regional Productivity: What is Behind Them?", Country Report 18/331, Washington.

,2019, “A Strategy for IMF Engagement on Social Spending,” Policy Paper No. 19/016, Washington.

Malo, M., 2015, "Labour Market Measures in Spain 2008-13: The Crisis and Beyond", International Labor Organization, Geneva.

Ministry of Economy and Business of Spain, 2019, Stability Programme Update, 2019-22.

Ministry of Health, Consumer Affairs, and Social Welfare of Spain, 2016, Report on Minimum Income Schemes, Year 2016, (Informe de Rentas Mínimas de Inserción), available at: https://www.mscbs.gob.es/ssi/familiasInfancia/ServiciosSociales/docs/Informe2016.pdf

Rodríguez-Cabrero, G., Arriba, A., Marbán, V. and F.J. Moreno-Fuentes, F.J., 2015, 'ESPN Thematic Report on integrated support for long-term unemployed: Spain'. European Social Policy Network.

Oderkirk, J., 2017, "Readiness of Electronic Health Record Systems to Contribute to National Health Information and Research", OECD, Health Working Papers, No. 99.

OECD, 2014, Teaching and Learning International Survey 2013. ,2018a, Economic Surveys: Spain. ,2018b, Overview of the education system (EAG 2018). , 2018c, Education Policy Outlook: Putting Student Learning at the Center. ,2018d, Education at a Glance 2018. , 2018e, A Broken Social Elevator? How to Promote Social Mobility.

Stepanyan, A. and J. Salas, forthcoming, "Distributional Implications of Labor Market Reforms: Learning from Spain's Experience."

Tatsiramos, K., 2014, “Unemployment Benefits and Job Match Quality: Do Unemployment Benefits Help Those Seeking Work to Obtain Better Jobs?", IZA World of Labor 44. 